Mr Zoran Ristić. pukovnik, dipl. inž.

Mile Davidović, dipl. inž.

Vojnotehnička akademija VJ

Beograd
UTICAJ KARAKTERISTIČNIH

PARAMETARA HIDRAULIČNE

KOČNICE TRZANJA NA PROCES

KOČENJA TRZAJUĆE MASE

UDC: 623.435 .2 .001 .575

\begin{abstract}
Rezime:
$U$ radu je prikazan matematički model za određivanje karakterističnih parametara procesa kočenja trzajuce mase na oruđu. Usvojen je model hidraulične kočnice trzanja sa diskretnim rasporedom protočnih otvora u cilindru. Odredivanje površine otvora $i$ rastojanja među njima izvršeno je na osnovu pet kriterijuma relevantnih za proces kočenja. Za sve kriterijume usvojena su ograničenja s obzirom na veličine modula ubrzanja $i$ veličine maksimalne - početne $i$ krajnje brzine trzanja. Na primeru oruđa komentarisani su dobijeni rezultati $i$ uporedna analiza prema razmatranim kriterijumima.
\end{abstract}

Ključne reči: hidraulična kočnica, klip, protočna površina, put kočenja, vreme kočenja.

\title{
INFLUENCE OF HYDRAULIC BRAKES TYPICAL PARAMETERS ON THE PROCESS OF RECOILLING MASS BREAKING
}

\section{Summary:}

The mathematical model for providing typical parameters of the process of breaking of recoiling mass on an artillery gun is presented. The model of hydraulic brakes with some discreting distribution of orifice surfaces in the cylinder is defined. The orifice surfaces and distance between them are determined on the basis of five criteria relevant for breaking process. The limitations are defined for all criteria in consideration to the module acceleration value and the value of maximum initial and limited recoil velocity. The discussion off calculated results is given as wellas the comparative analysis according to the discussed criteria.

Key words: hydraulic brakes, piston, orifice surface, breaking path, breaking time.

\section{Uvod}

Poznato je da na veličinu sile otpora trzanju, odnosno na ponašanje trzajućih delova oruđa pri opalenju, najviše utiče sila otpora hidraulične kočnice (HK) trzanja. Prema podacima u široj literaturi, zavisno od vrste i tipa oruđa, HK trzanja apsorbuju od 50 do $80 \%$ ukupne energije trzajućih delova oruđa na zadanom pu- tu trzanja. U konstruktivnom smislu postoji više vrsta $\mathrm{HK}$ i one su, uglavnom, razvijene na konceptu ispunjenog cilindra kočnice fluidom, klipnjači sa klipom i protočnim površinama za proticanje fluida $u$ prostoru cilindra kočnice.

Po rasporedu i obliku protočnih otvora (tzv. unutrašnje armature) HK oruđa su specifično građene $u$ odno- 
su na uobičajena rešenja $\mathrm{HK}$, amortizera i sl. u drugim uređajima.

Pouzdanost režima rada $\mathrm{HK}$ zavisi od više faktora, a prvenstveno se obezbeđuje ograničenjima veličine maksimalnog pritiska u cilindru kočnice, modulom ubrzanja klipa, što uslovljava i određena ograničenja pri izboru dimenzija HK.

Pri projektovanju HK osnovni problem sastoji se $\mathrm{u}$ definisanju njenih dimenzija i određivanju površina prekrivanja protočnih otvora pri kretanju klipa ili određivanju površina otvora promenljivih prečnika i rastojanja između otvora koji obezbeđuju zadata ograničenja radnih pritisaka fluida i ubrzanja, tj. usporenja klipa.

$\mathrm{Na}$ primeru šeme nezavisne $\mathrm{HK}$ jednostavne konstrukcije analiziran je proces kočenja trzajuće mase. Pri tome su raspored i dimenzije protočnih otvora određeni prema sledećim kriterijumima: minimalni put kočenja, minimalno vreme kočenja, jednak skok ubrzanja pri prekrivanju protočnih otvora, ravnomerno apsorbovanje kinetičke energije kretanja i jednako rastojanje između otvora za proticanje fluida. U svim varijantama definisano je ograničenje po maksimalnom ubrzanju klipa, a veličine početne i krajnje brzine kretanja trzajuće mase su poznate.

\section{Kriterijumi za određivanje parametara HK}

Na slici 1 prikazana je šema modela HK sa diskretnim rasporedom protočnih otvora jednostavne konstrukcije.

Energija trzajućih delova oruđa pri pomeranju klipa kočnice smanjuje se usled rada sila otpora, koji nastaje pri istiskivanju tečnosti iz radnog prostora II kroz otvore u prostor III, a odatle $u$ prostor IV kmpenzacionog rezervoara.

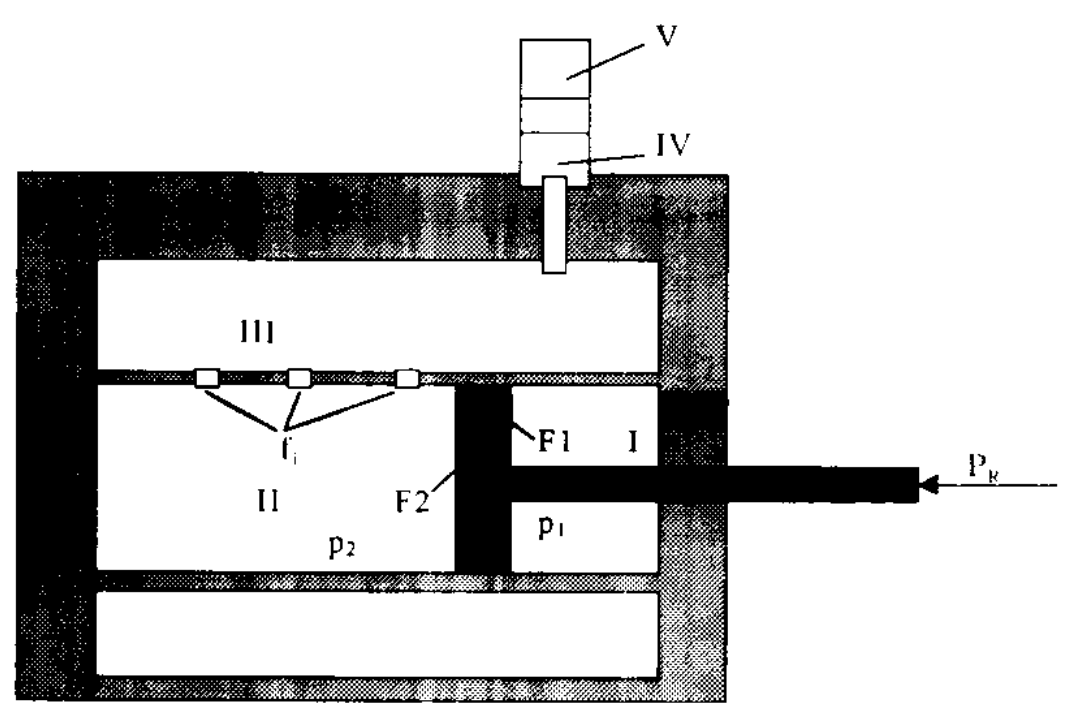

Sl. 1 - Sema modela $H K$

Trzajući delovi čvrsto vezani sa klipnjačom, pod delovanjem impulsa sile trzanja, naglo se ubrzavaju iz stanja mirovanja i kreću brzinom $\mathrm{v}_{\mathrm{o}}=\mathrm{v}_{\max }$. Pomeranjem klipa unutar cilindra kočnice uspostavlja se kretanje fluida pri čemu se znatan deo kinetičke energije utroši na savladavanje unutrašnjih otpora usled sila trenja fluida i otpora pri kretanju kroz protočne otvore. Usvaja se da nema gubitaka tečnosti u cilindru kočnice na mestu klipa i klipnjače. Uz date napomene $\mathbf{i}$ oznake prema slici 1 jednačina kretanja klipa glasi, [1]:

$$
\mathrm{mi}=\mathrm{P}_{\mathrm{n}}-\mathrm{p}_{2} \mathrm{~F}_{2}
$$

$P_{n}=P_{R}+p_{1} F_{1}-P_{t}-$ rezultantna sila

$\mathrm{p}_{2}=\frac{\zeta_{\rho}}{2} \mathrm{~F}_{2}{ }^{2} \frac{\mathrm{v}^{2}}{\mathrm{f}^{2}(\mathrm{x})}-$ pritisak tečnosti

gde je:

m - masa klipa kočnice i trzajućih delova,

$\mathrm{x}$ - pomak klipa,

$\mathrm{v}$ - brzina klipa,

$F_{1}, F_{2}$ - efektivne površine klipa,

$\mathrm{P}_{\mathrm{t}} \quad$ - sila trenja zida cilindra i klipa,

$P_{R}$ - rezultanta spoljašnjih sila,

$\mathrm{p}_{1}, \mathrm{p}_{2}$ - pritisci $\mathrm{u}$ šupljinama cilindra hidrauličke kočnice, 
P - gustina tečnosti,

$\zeta$ - koeficijent otpora struje (usvaja se konstantna vrednost),

f - površina otvora.

Pretpostavlja se da je spoljašnja sila jednaka sili trenja i sili vraćanja, odnosno $P_{n}=0$. Za prelaz na bezdimenzionalne promenljive iskoristiće se odnosi [1]:

$\frac{\mathrm{dv}}{\mathrm{dt}}=\frac{\mathrm{a}_{\Pi}}{2} \frac{\mathrm{du}}{\mathrm{d} \tau} ; \mathrm{v}=\frac{\mathrm{v}_{0}}{2} \mathrm{u}$;

$\mathrm{x}=\mathrm{x}_{\Pi \mathrm{I}} \xi ; \mathrm{t}=\mathrm{t}_{\Pi} \tau ; \mathrm{f}=\mathrm{f}_{\mathrm{y}} \mathrm{r} \mathrm{p}=\mathrm{p}_{\mathrm{c}} \sigma$,

gde su:

$u, \xi, \tau, v, \sigma \varepsilon$ brzina, pomak, vreme, površina otvora i pritisak,

$\mathbf{x}_{\Pi}, \mathrm{t}_{\Pi}, \mathrm{f}_{\mathbf{y}}, \mathrm{p}_{\mathrm{c}}-$ promenljive,

vo - brzina klipa i trzajuce mase $u$ trenutku kontakta,

$a_{\Pi} \quad-$ konstanta.

Promenljive se određuju po formulama:

$$
\begin{gathered}
t_{\Pi}=-\frac{v_{0}}{a_{I I}}, x_{\Pi I}=-\frac{v_{0}^{2}}{2 a_{\Pi I}}, \\
f_{y}=F_{2} \frac{v_{0}}{2} \sqrt{\frac{\zeta_{\rho}}{2 p_{c}}}, p_{c}=\frac{m a_{\Pi}}{F_{2}} .
\end{gathered}
$$

Posle zamene izraza (2) i (3) u (1) dobija se jednačina kretanja klipa hidrauličke kočnice $u$ bezdimenzionalnom obliku:

$$
\frac{d u}{d \tau}=-\frac{2 u^{2}}{u^{2}(\xi)} .
$$

Rešavanjem jednačine (4), razdvajanjem promenljivih, kada površina protočnih otvora ostaje konstantna, $v_{i-1}=$ const, dobija se:

$$
u_{i}=u_{i-1} e^{-\frac{2 \Delta \xi_{1}}{v_{i-1}^{2}}},
$$

a vreme kretanja na tom rastojanju biće:

$$
\Delta \tau_{i}=\frac{v_{i-1}^{2}}{2}\left[\frac{1}{u_{i}}-\frac{1}{u_{i-1}}\right] .
$$

Diskretna promena površina otvora pri kretanju klipa daje skokovitu promenu ubrzanja pri prekrivanju narednog otvora:

$$
\Delta \mathrm{u}=-\left[\frac{2 \mathrm{u}_{\mathrm{i}}^{2}}{\mathrm{v}_{\mathrm{i}}{ }^{2}}-\frac{2 \mathrm{u}_{\mathrm{i}}{ }^{2}}{\mathrm{v}_{\mathrm{i}-1}^{2}}\right] \text {. }
$$

Put i vreme koç̌enja su:

$$
\xi_{T}=\sum_{i=1}^{n} \Delta \xi_{i}, \quad \tau_{T}=\sum_{i=1}^{n} \Delta \tau_{i} .
$$

\section{Minimalni put kočenja}

Izbor razmeštaja i veličine otvora pri minimalnom putu kočenja sa $n$ otvora i pri ograničenom modulu ubrzanja

$$
\left|\dot{\mathrm{u}}_{0}\right|_{\max }=-2,\left|\dot{\mathrm{u}}_{\mathrm{i}}\right|_{\max }=-2.5 \text {; }
$$

$i=1,2, \ldots, n$, dobijen je iz rešenja sistema jednačina oblika:

$$
\frac{\partial \xi_{\mathrm{T}}}{\partial \mathrm{u}_{\mathrm{i}}}=0, \mathrm{i}=1,2, \ldots,(\mathrm{n}-1)
$$

Pri tome se vrednosti početne brzine $u_{0}$ i krajnje brzine $u_{n}$ moraju poklapati sa zadatim vrednostima. Iz izraza (5) i (8) se dobija da je

$$
\xi_{T}=\sum_{i=1}^{n} \frac{v^{2}{ }_{i-1}}{2}-\ln \frac{u_{i-1}}{u_{i}} \text {. }
$$

Dalje je, na osnovu relacije

$$
\begin{array}{r}
\left|\dot{u}_{i}\right|_{\max }=\frac{2 u_{i}^{2}}{u_{i}}, \\
\xi_{T}=\left.\sum_{i=1}^{n} \frac{u^{2}{ }_{i-1}}{\mid u_{i-1}}\right|_{\max } \ln \frac{u_{i-1}}{u_{i}},
\end{array}
$$




$$
\frac{\partial \xi_{T}}{\partial u_{i}}=\frac{1}{\left|\dot{u}_{i-1}\right|_{\max }}\left[u_{i}+2 u_{i} \ln \frac{u_{i}}{u_{i+1}}-\frac{u_{i-1}^{2}}{u_{i}}\right]=0 \text {, odnosno }
$$

$1+2 \ln \frac{u_{i}}{u_{i+1}}-\left(\frac{u_{i-1}}{u_{i}}\right)^{2}=0$

$\left(\frac{u_{i}}{u_{i+1}}\right)^{2}=e^{\left(\frac{u_{i-1}}{u_{1}}\right)^{2}-1}$

Usvaja se da je:

$$
I_{i}=\left(\frac{u_{i}}{u_{i+1}}\right)^{2} \Rightarrow I_{i-1}=\left(\frac{u_{i-1}}{u_{i}}\right)^{2}
$$

pa je $I_{i}=e^{I_{i-1}-1}$.

Dalje je:

$I_{0}=\left(\frac{u_{0}}{u_{1}}\right)^{2} ; I_{1}=\left(\frac{u_{1}}{u_{2}}\right)^{2} ; \ldots I_{n-1}=\left(\frac{u_{n-1}}{u_{n}}\right)^{2}$ iz čega sledi

$$
I_{0} \cdot I_{1} \cdot I_{2} \cdot \ldots \cdot I_{n-1}=\left(\frac{u_{0}}{u_{n}}\right)^{2}=K_{0}
$$

Prema tome, metodom postupnog približavanja treba rešiti sistem jednačina (15), $(i=1,2, \ldots, n)$, uz uslov

$$
\prod_{i=0}^{n-1} I_{i}=K_{0} .
$$

Rezultati proračuna bezdimenzionalnih površina otvora $\Delta v_{i} i$ bezdimenzionalnih rastojanja između otvora $\Delta \xi_{\mathrm{i}}$ za $\mathrm{n}=6, \mathrm{u}_{0}=2, \mathrm{u}_{\mathrm{n}}=0,04$ dati su $\mathrm{u}$ tabeli 1 , kao varijanta $I$.

\section{Minimalno vreme kočenja}

Varijanta II $\mathrm{u}$ tabeli 1 dobijena je rešavanjem sistema jednačina

$$
\frac{\partial \tau_{T}}{\partial u_{i}}=0, i=1,2, \ldots,(n-1),
$$

pri čemu su ograničenja kao u varijanti I. Ovaj problem detaljnije je izložen u [2].

Na osnovu relacije $\left|\dot{\mathrm{u}}_{\mathrm{i}}\right|_{\max }=\frac{2 \mathrm{u}_{\mathrm{i}}^{2}}{\mathrm{v}_{\mathrm{i}}}$, iz (6) dobija se da je:

$$
\Delta \tau_{j}=\frac{1}{\left.\dot{u}_{i-1}\right|_{\max }}\left[\frac{u_{i-1}^{2}}{u_{i}}-u_{i-1}\right]
$$

Uvrštavanjem ovog izraza $u$ relaciju (8), iz (17) sledi:

$$
\frac{\partial \tau_{T}}{\partial u_{i}}=\frac{1}{\left|u_{i-1}\right|_{\max }}\left[\frac{2 u_{i}}{u_{i+1}}-\frac{u_{i-1}^{2}}{u_{i}^{2}}-1\right]=0,
$$

odnosno

$$
2 \frac{u_{i}}{u_{i+1}}-\left(\frac{u_{i-1}}{u_{i}}\right)^{2}=1 .
$$

Usvaja se:

$$
I_{i}=\frac{u_{i}}{u_{i+1}} \Rightarrow I_{i-1}=\frac{u_{i-1}}{u_{i}} \text { pa je }
$$

$I_{i}=\frac{1}{2}\left[1+I^{2}{ }_{i-1}\right], \quad i=1,2, \ldots, n$

uz uslov:

$$
\prod_{i=0}^{n-1} I_{i}=C_{0}
$$

Jednak skok ubrzanja

Razmotriće se rad hidrauličke kočnice kada su raspored $\mathrm{i}$ veličina ot- 
Zbirni prikaz po svim kriterijumima

\begin{tabular}{|c|c|c|c|c|c|c|c|c|c|c|c|}
\hline & & $\mathrm{u}_{\mathrm{i}}$ & $\Delta \Theta_{\mathrm{i}}$ & $\Delta \xi_{\mathrm{i}}$ & $\mathrm{f}_{\mathrm{i}}\left(\mathrm{cm}^{2}\right)$ & $\mathrm{d}_{\mathrm{i}}(\mathrm{cm})$ & $\mathrm{v}_{\mathrm{i}}(\mathrm{m} / \mathrm{s})$ & $\mathrm{x}_{\mathrm{i}}(\mathrm{m})$ & $t_{1}(s)$ & $\mathrm{p}_{2 \mathrm{~m}}$ & $a_{\max }$ \\
\hline \multirow{4}{*}{ 曔 } & 0 & 2,0 & 0,0 & 0,0 & & & & & & \multirow{7}{*}{ 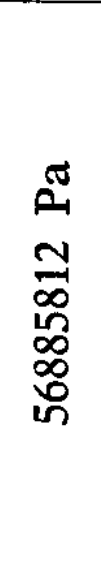 } & \multirow{7}{*}{$\sum_{a}^{n}$} \\
\hline & 1 & 1,819 & 0,373 & 0,190 & 0,940 & 1,094 & 12,059 & 0,107 & 0,008 & & \\
\hline 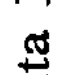 & 2 & 1,408 & 0,367 & 0,338 & 0,924 & 1,085 & 9,338 & 0,298 & 0,026 & & \\
\hline & 3 & 1,009 & 0,358 & 0,265 & 0,900 & 1,071 & 6,687 & 0,447 & 0,045 & & \\
\hline & 4 & 0,627 & 0,341 & 0,193 & 0,859 & 1,046 & 4,159 & 0,556 & 0,066 & & \\
\hline & 5 & 0,284 & 0,307 & 0,125 & 0,773 & 0,992 & 1,883 & 0,626 & 0,092 & & \\
\hline $\begin{array}{lll}0 \\
\end{array}$ & 6 & 0,040 & 0,218 & 0,063 & 0,549 & 0,836 & 0,265 & 0,662 & 0,151 & & \\
\hline \multirow{7}{*}{ 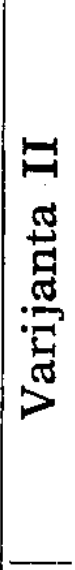 } & 0 & 2,0 & 0,0 & 0,0 & & & & & & \multirow{7}{*}{ 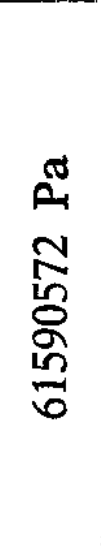 } & \\
\hline & 1 & 1,549 & 0,614 & 0,511 & 1,486 & 1,376 & 10,272 & 0,266 & 0,023 & & \\
\hline & 2 & 1,005 & 0,487 & 0,416 & 1,178 & 1,225 & 6,664 & 0,482 & 0,049 & & है \\
\hline & 3 & 0,595 & 0,366 & 0,212 & 0,887 & 1,062 & 3,947 & 0,592 & 0,071 & & 0 \\
\hline & 4 & 0,309 & 0,256 & 0,093 & 0,619 & 0,888 & 2,051 & 0,641 & 0,088 & & $\sqrt{7}$ \\
\hline & 5 & 0,131 & 0,159 & 0,033 & 0,385 & 0,700 & 0,872 & 0,658 & 0,101 & & \\
\hline & 6 & 0,040 & 0,082 & 0,008 & 0,198 & 0,502 & 0,265 & 0,662 & 0,111 & & \\
\hline \multirow{7}{*}{$\begin{array}{l}\mathrm{g} \\
\bar{J}\end{array}$} & 0 & 2,0 & 0,0 & 0,0 & & & & & & \multirow{7}{*}{ 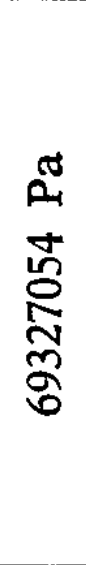 } & \\
\hline & 1 & 1,042 & 0,857 & 1,043 & 1,954 & 1,577 & 6,908 & 0,482 & 0,051 & & \\
\hline & 2 & 0,543 & 0,446 & 0,283 & 1,018 & 1,139 & 3,599 & 0,613 & 0,078 & & है \\
\hline & 3 & 0,283 & 0,233 & 0,077 & 0,530 & 0,822 & 1,875 & 0,649 & 0,092 & & 6 \\
\hline & 4 & 0,147 & 0,121 & 0,021 & 0,276 & 0,593 & 0,977 & 0,659 & 0,099 & & $\tilde{\tilde{N}}$ \\
\hline & 5 & 0,077 & 0,063 & 0,006 & 0,144 & 0,428 & 0,509 & 0,661 & 0,103 & & \\
\hline & 6 & 0,040 & 0,033 & 0,002 & 0,075 & 0,309 & 0,265 & 0,662 & 0,105 & & \\
\hline \multirow{7}{*}{ 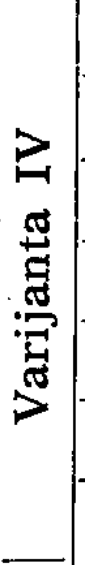 } & 0 & 2,0 & 0,0 & 0,0 & & & & & & \multirow{7}{*}{ 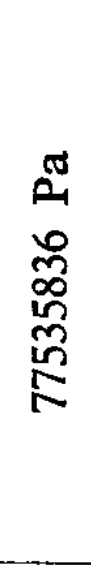 } & \multirow{7}{*}{ 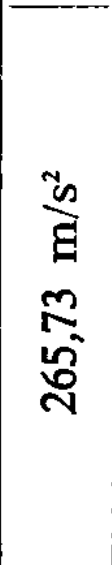 } \\
\hline & 1 & 1,826 & 0,156 & 0,146 & 0,336 & 0,654 & 12,105 & 0,060 & 0,005 & & \\
\hline & 2 & 1,633 & 0,172 & 0,149 & 0,372 & 0,688 & 10,828 & 0,122 & 0,010 & & \\
\hline & 3 & 1,414 & 0,196 & 0,153 & 0,422 & 0,733 & 9,378 & 0,185 & 0,016 & & \\
\hline & 4 & 1,155 & 0,232 & 0,162 & 0,500 & 0,798 & 7,659 & 0,252 & 0,024 & & \\
\hline & 5 & 0,817 & 0,302 & 0,185 & 0,652 & 0,911 & 5,419 & 0,329 & 0,036 & & \\
\hline & 6 & 0,040 & 0,695 & 0,806 & $1,499^{\circ}$ & 1,382 & 0,265 & 0,662 & 0,433 & & \\
\hline \multirow{7}{*}{ 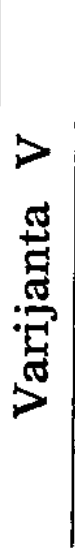 } & 0 & 2,0 & 0,0 & 0,0 & & & & & & \multirow{7}{*}{ 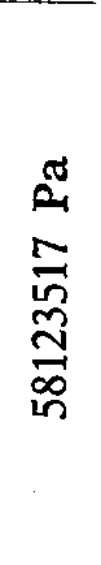 } & \multirow{7}{*}{$\begin{array}{l}\tilde{E} \\
\text { à } \\
\text { 尺్ } \\
\text { ू̆ }\end{array}$} \\
\hline & 1 & 1,765 & 0,210 & 0,200 & 0,524 & 0,816 & 11,702 & 0,110 & 0,009 & & \\
\hline & 2 & 1,503 & 0,234 & 0,200 & 0,583 & 0,862 & 9,967 & 0,221 & 0,019 & & \\
\hline & 3 & 1,205 & 0,267 & 0,200 & 0,665 & 0,920 & 7,988 & 0,331 & 0,031 & & \\
\hline & 4 & 0,854 & 0,314 & 0,200 & 0,782 & 0,998 & 5,661 & 0,441 & 0,048 & & \\
\hline & 5 & 0,430 & 0,379 & 0,200 & 0,944 & 1,096 & 2,851 & 0,552 & 0,076 & & \\
\hline & 6 & 0,029 & 0,359 & 0,200 & 0,894 & 1,067 & 0,191 & 0,662 & 0,275 & & \\
\hline
\end{tabular}


vora određeni na osnovu kriterijuma jednakog skoka ubrzanja. Traži se raspored otvora koji obezbeđuje jednak skok ubrzanja (7) pri prekrivanju narednog otvora:

$$
\Delta \dot{\mathrm{u}}=\text { const, }
$$

pri maksimalnom modulu ubrzanja:

$$
|\dot{u}|_{\max }=\frac{2 u_{i}^{2}}{v_{i}^{2}}=2,5 \text {. }
$$

Koristeći izraz (24), jednačina (7) dobija oblik:

$$
\Delta \dot{\mathrm{u}}_{\mathrm{i}}=-2,5\left(1-\frac{\mathrm{u}_{\mathrm{i}}^{2}}{\mathrm{u}_{\mathrm{i}-1}^{2}}\right) .
$$

$\mathrm{Na}$ osnovu (23) i (25) sledi da odnos brzina na kraju i na početku svakog dela mora biti konstantan. Ako je:

$$
\frac{u_{i}}{u_{i-1}}=b, \quad b<1 .
$$

tada je:

$$
u_{1}=b \cdot u_{0} ; u_{2}=b^{2} \cdot u_{0} ; \ldots u_{n}=b^{n} \cdot u_{0} .
$$

Iz ovog odnosa dobija se zavisnost broja otvora $n$ od zadate početne $u_{0}$ i krajnje brzine $u_{n}$ :

$$
\mathrm{n}=\frac{i \ln \frac{\mathrm{u}_{\mathrm{n}}}{\mathrm{u}_{0}}}{\sqrt{\ln \mathrm{b}}}
$$

Znači, što je b manje, što odgovara manjem skoku ubrzanja (25), to je veći broj potrebnih otvora $n$.

Rastojanje među otvorima, pri tome, biće:

$$
\Delta \xi_{\mathrm{i}}=0.4 \mathrm{u}_{0}^{2} \mathrm{~b}^{2^{(\mathrm{i}-1)}} \ln \mathrm{b}^{-1} .
$$

Rezultati proračuna površina $\Delta v_{i}$ i rastojanja među njima $\Delta \zeta_{\mathrm{i}}$, za $n=6$, $\mathrm{u}_{0}=2,0, \mathrm{u}_{\mathrm{n}}=0,04, \mathrm{uz}$ ispunjavanje uslova (23), (24) i (26), dati su u tabeli 1 kao varijanta III.
Jednak gubitak kinetičke energije

Ako se raspored i veličina otvora odredi iz uslova jednakog gubitka kinetičke energije pri kretanju klipa od i-tog do (i+1)-og otvora, znači da je:

$$
\left(\frac{\mathrm{u}_{0}^{2}-\mathrm{u}_{\mathrm{n}}^{2}}{\mathrm{n}}\right)=\mathrm{C}=\text { const } \text {. }
$$

Brzina $u_{i}$ računa se iz izraza:

$$
u_{i-1}^{2}-u_{i}^{2}=C \text {, }
$$

a pomak klipa i vreme iz relacija (10) i (6). Dobijene dimenzije otvora $i$ rastojanja između njih date su u tabeli 1 , kao varijanta IV.

\section{Jednako rastojanje medu otvorima}

Kada je zadat put kočenja $\left(\xi_{\mathrm{T}}\right)$, veličina otvora dobija se na osnovu jednakog rastojanja među njima:

$$
\Delta \xi_{\mathrm{i}}=-\frac{\xi_{\mathrm{T}}}{\mathrm{n}}=\mathrm{d}=\mathrm{const}
$$

Na osnovu izraza (10) sledi da je:

$$
\frac{u_{i-1}^{2}}{2} \ln \frac{u_{i}}{u_{i-1}}=d
$$

Površine otvora i ubrzanje klipa dobijaju se iz (32) i (24), a vreme iz (6).

Dobijeni rezultati dati su $u$ tabeli 1, kao varijanta $\mathrm{V}$.

\section{Programski model za rešavanje problema}

$\mathrm{Za}$ numeričko određivanje parametara HK trzanja, definisanih prema datim kriterijumima, izrađeno je odgovarajuće programsko rešenje. Algoritam programskog rešenja sistema jednačina (15) i (21), uz uslov (16) i (22), metodom postupnog približenja, dat je na slici 2. 


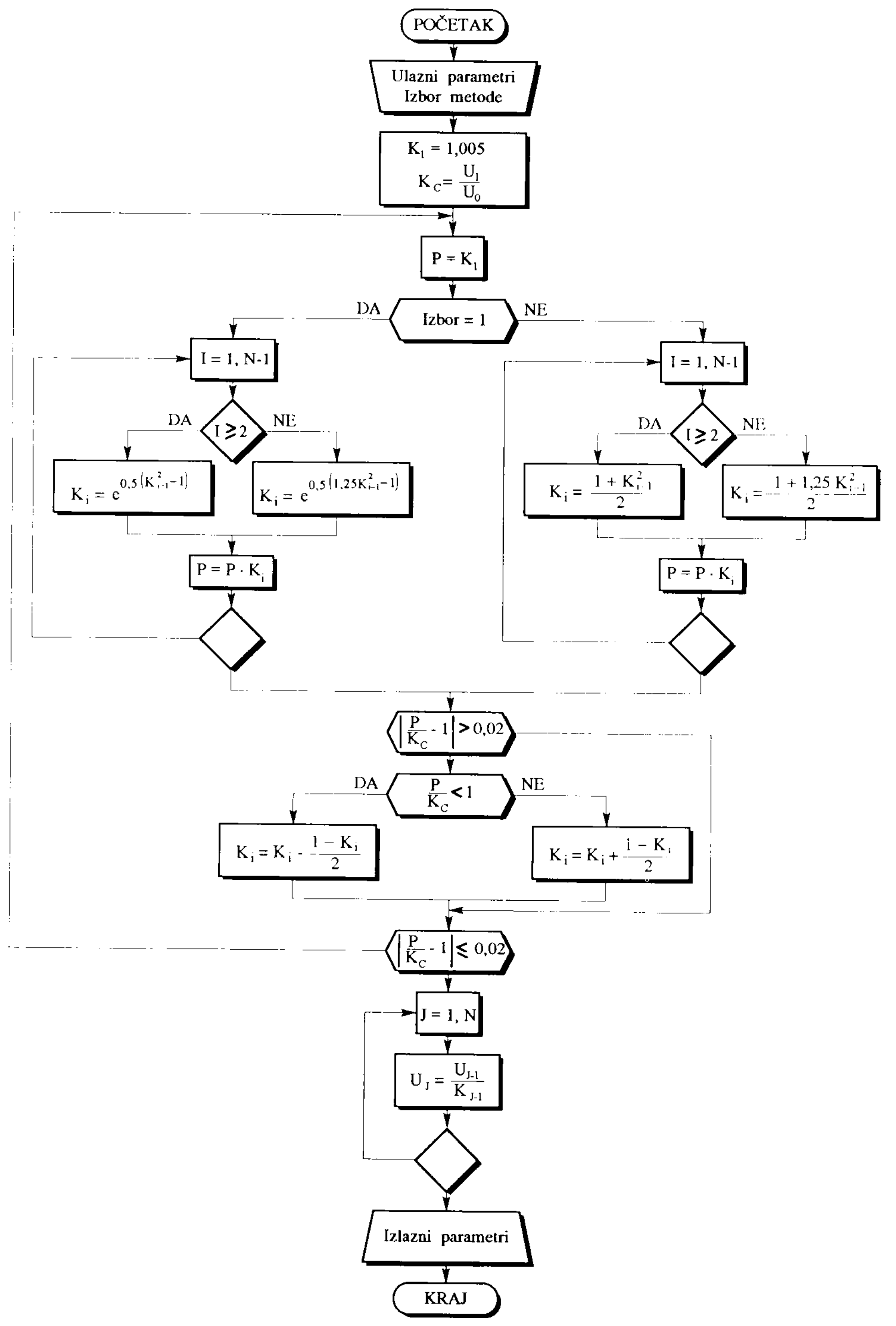

Sl. 2 - Algoritam programskog rešenja 
Programsko rešenje čine dve celine, glavni program $\dot{i}$ blok potprograma (procedura). Glavni program služi za unos određenih polaznih podataka, pruža mogućnost korisniku da izabere kriterijum na osnovu kojeg će se vršiti proračun i upravljati radom potprograma. Drugi deo programa sastoji se od više procedura. Procedure KOEF1 do KOEF5 služe za proračun koeficijenata po kriterijumima: minimalni put kočenja, minimalno vreme kočenja, jednak skok ubrzanja pri prekrivanju otvora, ravnomerno apsorbovanje kinetičke energije trzanja i jednako rastojanje među otvorima za proticanje fluida.

Posebnim izborom opcije moguć je zbirni prikaz rezultata proračuna po svim kriterijumima. Ova opcija omogućava komparativni prikaz rezultata i izbor optimalnog kriterijuma za proračun hidraulične kočnice trzanja.

Programsko rešenje rađeno je $u$ PASKALU.

\section{Upoređivanje kriterijuma za izbor parametara $\mathbf{H K}$}

Upoređivanje proračunskih veličina površina otvora za proticanje $\left(\Delta \Theta_{i}\right)$ i rastojanja među njima $\left(\Delta \xi_{i}\right)$, prema datim kriterijumima (varijante I do V), ilustrovano je na primeru oruđa TN za koje su definisani sledeći podaci:

- početna brzina trzanja $\mathrm{v}_{0}=$ $=\mathrm{v}_{\mathrm{m}}=13,26(\mathrm{~m} / \mathrm{s})$,

(m),

- prečnik cilindra $\mathrm{HK} D=0,120$

- masa trzajućih delova $\mathrm{m}=$ $=3300(\mathrm{~kg})$, $\left(\mathrm{kg} / \mathrm{m}^{3}\right)$,

- gustina tečnosti HK $p=900$

- koef. gubitka tečnosti $\zeta=1,14$,

- put kočenja $\mathrm{x}_{\mathrm{t}}=0,662(\mathrm{~m})$,

- broj otv. za protic. tečnosti $\mathrm{n}=6$.
Upoređivanje dobijenih vrednosti za maksimalne pritiske $\left(\mathrm{p}_{2 \mathrm{~m}}\right) \mathrm{u} \mathrm{HK}$, ubrzanja $a_{\max } i$ vremena kočenja $\left(t_{i}\right)$, prema tabeli 1 , omogućuje da se utvrdi kako izabrani kriterijumi utiču na proces kočenja i kako se menjaju dimenzije i površine otvora i njihov raspored sa pomakom klipa. Prema dobijenim rezultatima, varijanta IV, zasnovana na kriterijumu ravnomernog apsorbovanja kinetičke energije kretanja, nije prihvatljiva zbog visokog pritiska $\mathrm{p}_{2 \mathrm{~m}}=77,5 \mathrm{MPa}$ i velikog vremena kočenja $t_{t}=0,433 \mathrm{~s}$. Varijanta $\mathrm{V}$, izvedena iz uslova jednakog rastojanja između otvora, iako u konstruktivnom smislu najjednostavnija, daje relativno veliko vreme kočenja $t_{t}=0,275 \mathrm{~s}$. Ovakav raspored otvora može se prihvatiti u slučaju ako vreme kočenja nije odlučujući parametar. U varijanti III dobijeno vreme kočenja $t_{t}=0,105$ $s$ je najmanje $u$ odnosu na sve varijante, ali prema varijantama I i II daje veći pritisak u cilindru $H K, p_{2 m}=69,3$ $\mathrm{MPa}$, i vrlo mala rastojanja između poslednja tri otvora za proticanje. Varijanta I, prema kriterijumu minimalnog puta kočenja i II prema minimalnom vremenu kočenja su optimalne, kako po vremenu kočenja, tako i po vrednosti maksimalnog pritiska $\mathrm{p}_{2 \mathrm{~m}}=$ $=56,8 \mathrm{MPa} \mathrm{i} \mathrm{p}_{2 \mathrm{~m}}=61,6 \mathrm{MPa}$. Zavisnost brzine kočenja od puta kočenja na slici 3 za sve varijante po karakteru promene prilično je ujednačena, osim za varijantu IV prema kriterijumu jednakog apsorbovanja kinetičke energije kretanja.

U svim razmatranim varijantama pri proračunu pada ubrzanja prema (7) pretpostavljena je trenutna promena površine otvora pri prekrivanju sa klipom. Pri tome se svaki otvor može izvesti u obliku proreza ili slaganjem u nizu po obodu poprečnog preseka cilindra HK. Na slici 4 data je promena sile otpora $\mathrm{HK}$ u zavisnosti od puta kočenja. 


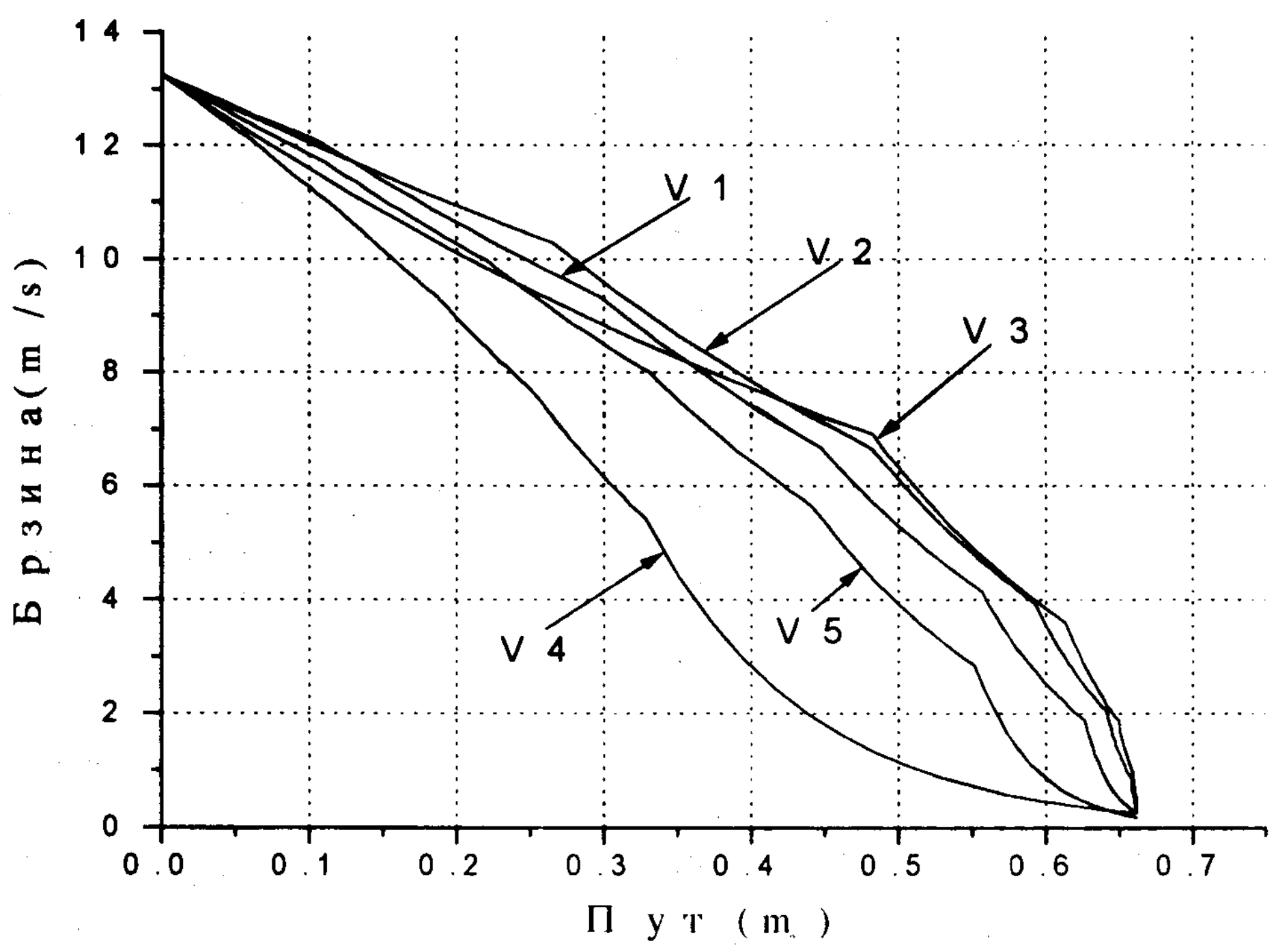

Sl. 3 - Zavisnost brzine od puta kočenja

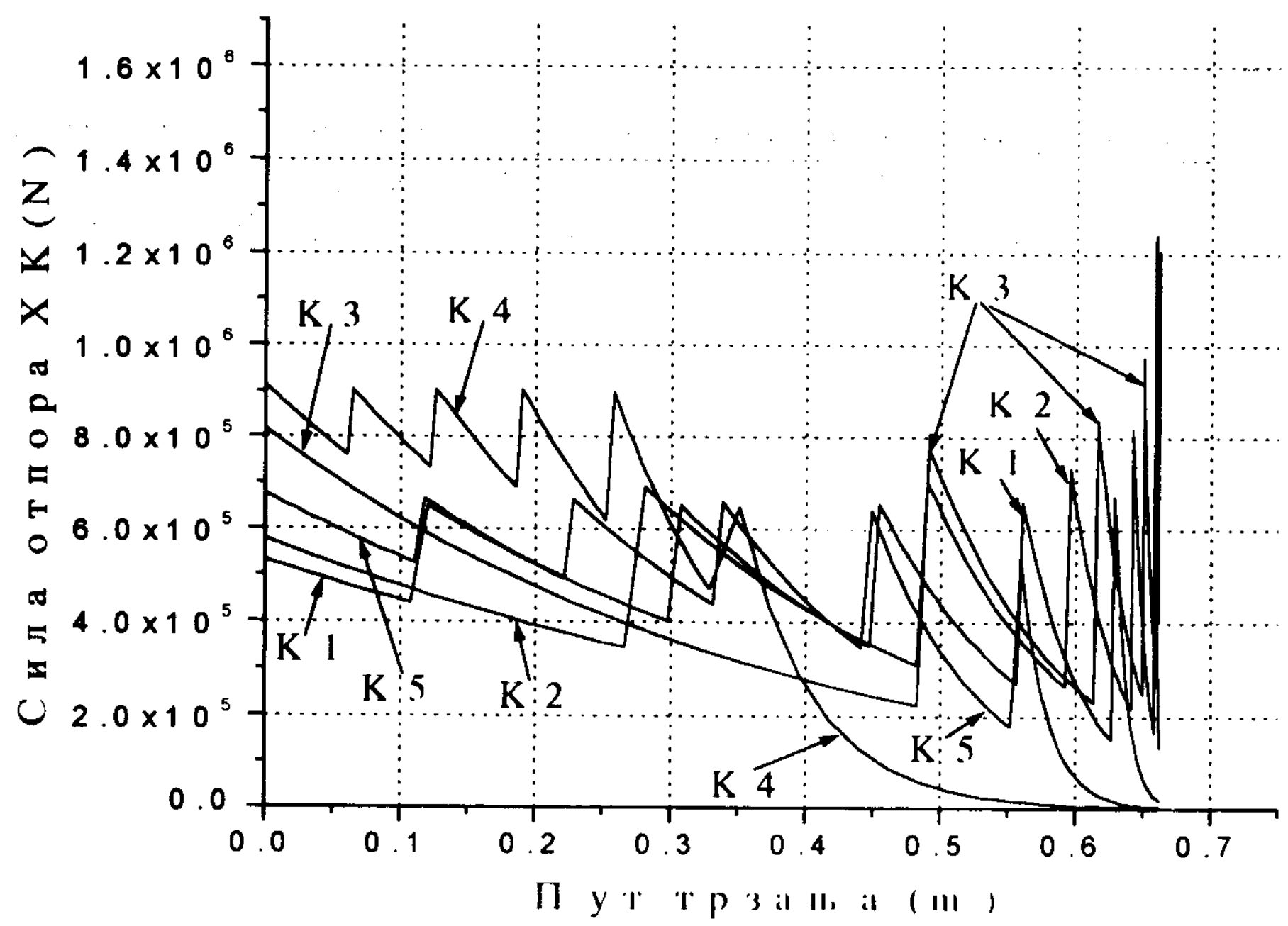

Sl. 4 - Promena sile otpora HK od puta 
Promena sile otpora kočnice trzanja ima testerast karakter promene za sve varijante proračuna. Nagli skokovi sile otpora nastaju usled trenutnog prekrivanja pojedinih otvora, pri čemu dolazi do diskretnog smanjivanja ukupne površine za proticanje tečnosti iz prostora II u prostor III (sl. 1), odnosno diskretnog povećanja lokalnih brzina strujanja. Na kraju procesa trzanja, ukoliko dođe do prekrivanja poslednjeg otvora, dolazi do naglog skoka sile otpora usled malog koeficijenta stišljivosti tečnosti. Ovakav oblik promene sile otpora uzrokuje nestalan rad kočnice trzanja i nije preporučljiv za primenu. Ukoliko bi se umesto diskretnog rasporeda otvora primenili kontinuirani otvori po obodu unutrašnjeg cilindra kočnice, promena sile otpora kočnice trzanja bila bi kontinuirana. Konstrukcija ovakve kočnice znatno je jednostavnija od dosad primenjivanih kočnica trzanja. Sa slike 4 vidi se da kriterijumi I i V daju najravnomerniju rasnodelu sile otpora, a najveći skokovi sile otpora na kraju trzanja dobijaju se po kriterijumu III.

Literatura:

[1] Cuhanova, E. A., Jašina, M. A.: Rascet gidrodempfera s učetom diapazona izmenenija massi. Mašinostroenie, 1981.

\section{Zaključak}

Razmatrani model jednostavne HK sa diskretnim rasporedom otvora za proticanje prema datim kriterijumima omogućuje željeni izbor potrebnih parametara procesa kočenja koji mogu biti odlučujući za ukupno apsorbovanje kinetičke energije trzajuće mase usled impulsa trzanja. Definisanim ograničenjima za veličine maksimalnog pritiska $\mathrm{u}$ cilindru $\mathrm{HK}$, kao i ubrzanja pokretnih delova, može se obezbediti potrebna pouzdanost rada HK i smanjenje uticaja inercijalnih sila u procesu kočenja kretanja trzajuće mase.

Ovakvim modelom, i u slučaju da se ne može u potpunosti obezbediti potreban zakon kočenja za promenljive dužine trzanja, mogu se znatno pojednostaviti konstruktivna rešenja HK. U tom smislu predloženi model treba dalje istražiti i dograditi, kako bi se obezbedili svi zahtevi HK trzanja u procesu kočenja na oruđima različitih tipova.

[2] Cuhanova, E. A., Jašina, M. A. Rasčet parametrov gidrodempfera $s$ diskretno izmenjajosimsja oknami. Mašinostroenie, 1982.

[3] Ristić, Z.: Kočeno kretanje mase pomoću hidraulične kočnice VTG 1/97, str. 63-70. 